\title{
Cutaneous Polyarteritis Nodosa (cPAN) in a 5 Years Old Girl
}

\author{
Shafique Rehman Arain ${ }^{1}$, Tahira Perveen Umer $^{2}$ and Lubna Nazir ${ }^{3 *}$ \\ ${ }^{1}$ Rheumatology Fellow, Pakistan \\ ${ }^{2}$ Consultant Rehumatologist and Head of Department, Pakistan \\ ${ }^{3}$ Consultant Rheumatologist, Pakistan \\ *Corresponding author: Lubna Nazir, Consultant Rheumatologist, Liaquat National Hospital, Pakistan
}

Submission: 眥January 17, 2018; Published: 眥 May 16, 2018

\begin{abstract}
Polyarteritis nodosa is a rare form of systemic vasculitis. Cutaneous polyarteritis nodosa (cPAN) is subtype of systemic PAN which predominantly affects the skin, extra-cutaneous findings include fever, malaise, myalgias, arthralgias, and neuropathy. The true incidence of cutaneous PAN is unknown. cPAN is recognized as a separate entity and is essentially a benign disorder which should be distinguished from systemic PAN, as the clinical course and management of the two conditions is different. In this case report, we have described a patient with fever and gangrene of both hands and feet. The patient underwent a very extensive workup in order to determine the cause of her condition, which finally turned out cPAN on skin biopsy.
\end{abstract}

\section{Conclusion}

cPAN although rare form of systemic vasculitis, its true incidence is yet unknown. Rheumatologist and Pediatrician should always think this rare disease whenever dealing a child with gangrene and systemic symptoms.

\section{Introduction}

Classic polyarteritis nodosa was the first systemic vasculitis to have been described. In 1866, Kussmaul and Maier [1] characterized this fatal condition which was originally called "periarteritis nodosa." It was not until 1931 that Lindberg [2] first recognized PAN limited to skin. Systemic polyarteritis nodosa is rare, the true incidence of cutaneous PAN is unknown [3]. Although cutaneous polyarteritis nodosa (cPAN) predominantly affects the skin, extracutaneous findings include fever, malaise, myalgias, arthralgias, and neuropathy. cPAN is recognized as a separate entity but there are no diagnostic criteria for cPAN [4]. cPAN is essentially a benign disorder and should be distinguished from systemic PAN, as the clinical course and treatment of these two conditions is different from each other. To our knowledge, we report first case of childhood cPAN in Pakistan.

\section{History of Presenting Illness}

5 years old girl, seen in rheumatology clinic with 6 months h/o sudden onset, high grade fever $\left(103 \mathrm{~F}^{\circ}\right)$, intermittent. Associated with rigors, chills, malaise and sweating. There were h/o body ache, headache and occasional vomiting during the episode of fever. Later on complaining of symmetrical polyarthralgias and polyarthritis of small and large joints, including small joints of both hands and feet, wrists, elbows, shoulders, knees and ankles. 2 months later, developed Raynaud's of all fingers and toes, which led to gangrene in all fingers of both hands and feet. No H/O sore throat, oral or genital ulcers, rash, bleeding, Alopecia or neurological symptoms.

\section{Physical Examination}

Looking ill, Pale with moon like face. Wt $18 \mathrm{~kg}$, HT $103 \mathrm{~cm}$ with BMI of 16.96. Gangrene of all fingers of left hand and 2nd, 4th and 5 th fingers of right hand with overlying crust formation. Gangrene of all toes of right foot and 2nd, 3rd, 4th and 5th toes of left foot with overlying crust formation. Infected ulceration at the borders of gangrene with purulent discharge. Her Pulse was $112 \mathrm{~b} / \mathrm{min}$ with Temp: of $99 \mathrm{~F}^{\circ}$ and $\mathrm{R} / \mathrm{R} 16 \mathrm{br} / \mathrm{min}$. Sub-vitals were un-remarkable except she was mildly anemic.

Examination of Wrists, shoulders, knees, ankles: S1, T1, FROM, while systemic examination including CVS, CNS, Respiration and Abdomen were un-remarkable. Duplex ultrasound of both upper and lower limbs revealed no plaque formation or occlusion. There was no evidence of DVT. Skin punch biopsy: The underlying dermis shows mild perivascular lymphocytes infiltrate and macrophages, with intimal proliferation and thrombosis of the artery. No evidence of malignacy. Biopsy report consistent with Vasculitis i.e., Cutaneous PAN.

\section{Final Diagnosis}

Cutaneus Polyartirits Nodosa (cPAN) (Figure 1). 


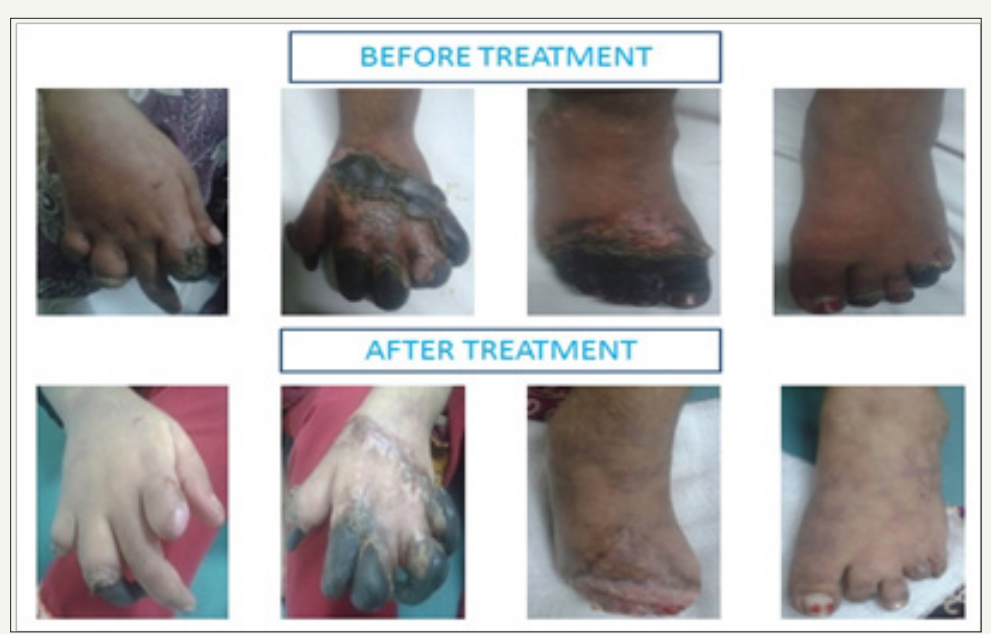

Figure 1

\section{Hospital Course}

She started on oral Prednisolon $1 \mathrm{mg} / \mathrm{kg}$ and broad spectrum antibiotics with poor response over 2 weeks. Keeping in view of her condition and after thorough search of literature she is given 3 cycles of Cyclophosphamide $375 \mathrm{mg} / \mathrm{m} 2$ every month while continued with Prednislolon, tapered to $2.5 \mathrm{mg}$. Her condition and lesions improved.

\section{Discussion}

Polyarteritis nodosa (PAN) is a rare vasculitis [5] in the pediatric population with approximately 140 cases reported in the literature. In most of the cases disease is limited to skin, joints, and muscles, while minority having involvement nerves. Systemic involvement in cPAN is uncommon except peripheral neuropathy, and progression to classical PAN is an exception. The pathogenesis of cutaneous PAN is not clearly understand and defined in the literature.

Cutaneous polyarteritis nodosa usually appears first as livedo reticularis, tender subcutaneous nodules, or cutaneous ulcerations [6]. Other findings include petechiae, purpura, cutaneous necrosis, auto-amputations, and local extra-cutaneous manifestations. This most commonly occurs on the legs [6,7]. In fact, the legs are affected $97 \%$ of the time, followed by the arms in $33 \%$, and the trunk in $8 \%$ [6]. The definitive diagnosis of cPAN is only made by skin biopsy. Laboratory abnormalities that are frequently encountered include mild anemia, moderate leukocytosis, and an elevated ESR [8]. Different from the systemic PAN, cPAN does not show any immunologic abnormalities that could be detected by ANCA, RA factor, diminished complement levels and cryoglobulin levels. However, these tests must be done to rule out other more severe forms of vasculitis or rheumatologic disorders [6]. There is a paucity of knowledge of the spectrum of clinical presentation and management of children with cPAN [9].

Mild cases, consisting of mainly nodules and livedo, may require only non-steroidal anti-inflammatory drugs (NSAIDs) or colchicines [10]. Patients refractory to more conservative treatment and those involving severe pain, ulcerations, necrosis, or extra-cutaneous symptoms such as myalgias, paresthesias, and arthralgias may require a more aggressive approach $[6,10]$.

Prednisolone $30 \mathrm{mg}$ daily or less is often effective, but a dosage of $1 \mathrm{mg} / \mathrm{kg} / \mathrm{d}$ may be required [6,10]. Additional medications may be necessary to maintain control of the disease and allow reduction in steroid dosage. Agents that have been used for this purpose include NSAIDs, colchicine, hydroxychloroquine, dapsone, azathioprine, cyclophosphamide, methotrexate, sulphapyridine, pentoxyphylline, and intravenous immunoglobulin $[6,11]$.

\section{References}

1. Kussmaul A, Maier K (1866) Ueber eine nicht bisher beschriebene eigenhümliche Arterienerkrankung (Periarteritis Nodosa), die mit Morbus Brightii und rapid fortschreitender allgemeiner Muskellähmung einhergeht. Dtsch Arch Klin Med 1: 484-518.

2. Lindberg K (1931) Ein beitrag zur kenntnis der periarteritis nodosa. Acta Med Scand 76(1-2): 183-225.

3. Borrie P (1972) Cutaneous polyarteritis nodosa. Br J Dermatol 87(2): 87-95.

4. Ozen A, Pistorio SM, Iusan, Bakkaloglu A, Herlin T, et al. (2010) EULAR/ PRINTO/PRES criteria for Henoch-Schonlein purpura, childhood polyarteritis nodosa, childhood Wegener granulomatosis and childhood Takayasu arteritis: Ankara Part II: final classification criteria. Ann Rheum Dis 69(5): 798-806.

5. Ozen S, Anton J, Arisoy N, Bakkaloglu A, Besbas N, et al. (2004) Juvenile polyarteritis: results of a multicenter survey of 110 children. J Pediatr 145(4): 517-522.

6. Daoud MS, Hutton KP, Gibson LE (1997) Cutaneous periarteritis nodosa: a clinicopathological study of 79 cases. Br J Dermatol 136(5): 706-713.

7. Nakamura T, Kanazawa N, Ikeda T, Yamamoto Y, Nakabayashi K, et al. (2009) Cutaneous polyarteritis nodosa: revisiting its definition and diagnostic criteria. Arch Dermatol Res 301(1): 117-121.

8. Diaz Perez JL, Winkelmann RK (1974) Cutaneous periarteritis nodosa. Arch Dermatol 110(3): 407-414.

9. Bansal NK, Houghton KM (2010) Cutaneous polyarteritis nodosa in childhood: a case report and review of the literature. Arthritis 2010: 687547. 
10. Choi SW, Lew S, Cho SD, Cha HJ, Eum EA, et al. (2006) Cutaneous polyarteritis nodosa presented with digital gangrene: a case report. J Korean Med Sci 21(2): 371-373.
11. Lobo I, Ferreira M, Silva E (2007) Cutaneous polyarteritis nodosa treated with intravenous immunoglobulins. J Eur Acad Dermatol Venereol 22: 880-882.

\section{(c) (i) \\ Creative Commons Attribution 4.0 International License}

For possible submissions Click Here
Submit Article

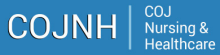

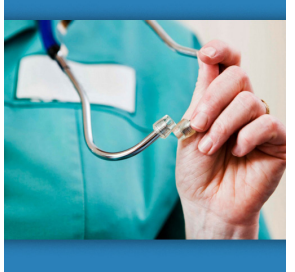

\section{COJ Nursing \& Healthcare}

Benefits of Publishing with us

- High-level peer review and editorial services

- Freely accessible online immediately upon publication

- Authors retain the copyright to their work

- Licensing it under a Creative Commons license

- Visibility through different online platforms 